\title{
A COMUNICAÇÃO NÃO VIOLENTA APLICADA AO CONTEXTO ESCOLAR DE MOSSORÓ/RN: UMA ANÁLISE DOS RELATOS DE EXPERIÊNCIAS DE FACILITADORES DE PRÁTICAS RESTAURATIVAS
}

\section{THE NON-VIOLENT COMMUNICATION APPLIED TO THE SCHOOL CONTEXT OF MOSSORÓ/RN: AN ANALYSIS OF THE REPORTS OF EXPERIENCES FROM FACILITATORS OF RESTAURATIVE PRACTICES}

Arthur Nunes Remígio

RESUMO: Este trabalho versa sobre a comunicação não-violenta aplicada ao contexto escolar de Mossoró/RN, sendo analisada a partir dos relatos de experiências de facilitadores de práticas restaurativas. Ele se dedica a responder à seguinte problemática: como aperfeiçoar a comunicação não violenta, no contexto escolar de Mossoró/RN, a partir dos relatos de experiências dos facilitadores de práticas restaurativas? Para tanto, estão definidos os objetivos específicos no intuito de apresentar o tema da CNV, analisar as dificuldades e contribuições observadas pelos facilitadores de práticas restaurativas e identificar maneiras de superar os obstáculos, além de aperfeiçoar e fortalecer a aplicação da CNV no contexto escolar. Por fim, chegou-se a resposta que para se aperfeiçoar a aplicação da CNV tem-se que superar o desconhecimento das práticas restaurativas pelas pessoas, como também problemas de aproximação com a administração das escolas e uma maior união entre família, comunidade que circunda a escola e o corpo docente administrativo.

Palavras-chave: Comunicação não-violenta; Escola; Práticas Restaurativas.

ABSTRACT: This article has as subject the non-violent communication applied to the scholar context of Mossoró/RN being analysed from the reports of experiences of facilitators of restaurative practices. It aims to answer the following problematic: how to improve the non-violent communication, in the schoool context of Mossoró/RN, from the reports of experiences of facilitators of restaurative practices? For that, the specific objectives have been defined aiming to present the theme of NVC, analise the difficulties and contributions seen by the facilitators of restaurative practices and identify ways to overcome the obstacles, besides perfecting strengthen the application of the NCV in the school context. Lastly, the answer that have been reached says that to improve the application of the NCV has to overcome the unfamiliarity of the restaurative practices by the people, plus that the problems of approaching the administration of the schools and a greater bond between family, community that surrounds the school and the administrative faculty.

Keywords: Non-violent communication; School; Restaurative practices. 


\section{INTRODUÇÃO}

O presente trabalho tem por objetivo investigar a aplicação das técnicas dialógicas da comunicação não-violenta $(\mathrm{CNV})$ dentro do contexto escolar da cidade de Mossoró/RN a partir dos relatos das experiências de facilitadores de práticas restaurativas. Este tema tem sua importância dado o contexto de tensões em que o Brasil se encontra com o acirramento da polarização política e também do aumento da presença na mídia de discursos que se utilizam de linguagens que instigam violência e separação. Diante disso, propor uma reflexão quanto à aplicação da técnica dialógica da comunicação não violenta proposta por Marshall B. Rosenberg dentro do ambiente escolar se evidencia como algo de grande importância de forma a se apresentar como um contrapeso às tensões hodiernas vividas na sociedade brasileira.

As técnicas de comunicação não-violenta foram absorvidas pelas práticas restaurativas e estas são utilizadas como forma de mediar conflitos em diversas partes do mundo. Como em qualquer ambiente que haja convivência humana, as escolas também estão sujeitas ao acontecimento de conflitos. Diante desse fato, é cabível a aplicação dessas práticas restaurativas dentro do contexto escolar, as quais já têm ações concretas nas escolas de Mossoró/RN. Desta forma, investiu-se o esforço desta pesquisa no intuito de responder a seguinte pergunta: como aperfeiçoar a comunicação não violenta, no contexto escolar de Mossoró/RN, a partir dos relatos de experiências dos facilitadores de práticas restaurativas?

Ao se ter em mente qual a problemática que se pretende dar alguma resposta, faz-se necessário traçar os objetivos do trabalho. De forma mais abrangente, foi definido que buscaremos investigar como pode ser aperfeiçoada a aplicação da comunicação não-violenta no contexto escolar de Mossoró/RN a partir dos relatos das experiências práticas de facilitadores de práticas restaurativas. Com o fito de atingir o objetivo geral, foram traçados os objetivos específicos. Dessa forma buscaremos apresentar como a comunicação não violenta se adequa enquanto técnica dialógica para tratar conflitos no ambiente escolar; analisar os desafios e as contribuições que a implementação da CNV tem gerado, a partir dos relatos das experiências dos facilitadores de práticas restaurativas, dentro do contexto escolar de Mossoró/RN e, por fim, busca-se identificar estratégias para superação dos obstáculos e meios de fortalecimento das práticas restaurativas vivenciadas no cenário escolar, para o pleno desenvolvimento da comunicação não violenta aplicada a ele.

No tocante à metodologia deste trabalho, esta foi construída a partir de pesquisa bibliográfica baseada em artigos de revista científica e livros cujo conteúdo faça relação com o tema que se aborda neste trabalho. Como também da análise das respostas fornecidas por meio de um questionário enviado por e-mail para alguns facilitadores de práticas restaurativas que realizaram ações nas escolas da cidade de Mossoró/RN. O critério utilizado para selecionar as pessoas participantes foi ter participado e concluído o curso de facilitação de práticas restaurativas, promovido pelo Ministério Público do Estado do Rio Grande do Norte (MPRN), e delimitou-se que seriam estudantes do curso de Direito da Universidade Federal Rural do Semiárido de Mossoró/RN.

No dia 26 de novembro de 2019, foram enviados e-mails para 14 facilitadores contendo o 
questionário (Apêndice 1) a ser respondido e o Termo de Consentimento Livre e Esclarecido (Apêndice 2). Desses e-mails, apenas 11 tiveram o recebimento confirmado pelas pessoas. Porém, apenas 7 foram respondidos, com o questionário preenchido até o fechamento da coleta de dados, que ocorreu em 29 de janeiro de 2020, sendo o último e-mail recebido em 09 de dezembro de 2019. O público deste trabalho se distribui entre alunos e alunas que estão entre o terceiro e o oitavo semestre do Curso de Direito na UFERSA de Mossoró/RN e tiveram suas formações teóricas concluídas em um lapso temporal de, aproximadamente, 01 ano e 09 meses a 07 meses da data em que responderam ao questionário.

Finalmente, cabe ainda dizer que este trabalho está dividido em três momentos. No primeiro capítulo, foi analisada a comunicação não violenta como técnica dialógica no contexto escolar para mediar conflitos. Nesta parte, discorreu-se sobre os princípios que norteiam a CNV e como a aplicação dela tem atuado no contexto escolar brasileiro. Chegando ao segundo capítulo, é nele que se encontra a análise das respostas dos facilitadores de práticas restaurativas obtidas através do questionário e, diante delas, a ideia é absorver as dificuldades enfrentadas e quais as contribuições observadas através da realização de ações envolvendo práticas restaurativas. No último capítulo, a pesquisa norteou-se de acordo com o intuito de trazer estratégias para fortalecer e aperfeiçoar as práticas restaurativas dentro do contexto escolar, tendo como meio para isso a participação da família, comunidade que circunda as escolas e o corpo docente-administrativo destas.

\section{A COMUNICAÇÃO NÃO VIOLENTA COMO TÉCNICA DIALÓGICA NO CONTEXTO ESCOLAR PARA MEDIAR CONFLITOS}

Quando buscamos fazer uma análise acerca da aplicação das técnicas da Comunicação NãoViolenta, devemos buscar as informações sobre elas na fonte, que é a obra de Marshall B. Rosenberg. Neste trabalho, relacionamos as técnicas propostas por ele com a aplicação destas no contexto escolar brasileiro e, mais especificamente, na cidade de Mossoró/RN.

Com o intuito de situar o leitor sobre como se dá a problemática das violências vividas dentro do espaço escolar, teremos como base o trabalho de Maria Angélica da Silva Costa Santos (2018) que coletou dados na rede escolar estadual de ensino do Estado de Sergipe.

Em seu trabalho, a pesquisadora apurou os dados a partir de 199 escolas da rede estadual de ensino do Sergipe e obteve dados que devem ligar nosso sinal de alerta sobre a situação das relações interpessoais que tem se desenvolvido nesses espaços.

Para corroborar com a ideia trazida anteriormente no tocante ao sinal de alerta sobre as relações humanas dentro das escolas dessa rede de ensino, tem-se que a partir dos relatos de pais, alunos, professores e demais agentes escolares, pôde-se traçar um pouco dos tipos de violência que fazem parte daquele convívio. Após apurarem-se os dados do questionário que foi passado pela pesquisadora, os dados se evidenciaram da seguinte forma: $51 \%$ das pessoas relataram sempre observarem ocorrências de violência verbal, enquanto 
17\% sempre presenciavam algum tipo de violência psicológica.

Como foi dito, esse dados preocupam, por evidenciarem uma alta incidência de casos de violência que, infelizmente, contaminam o ambiente escolar e podem prejudicar a boa convivência e toda a prática educativa que se espera dentro do ambiente escolar.

Comumente as escolas dispõem de mecanismos para apaziguar os conflitos que tomam contorno dentro de seus espaços, que são naturais, tendo em vista a vivência em sociedade naquele ambiente, e podem ocorrer entre os mais diversos agentes que estão inseridos ali. No caso da pesquisa de Santos (2018), observou-se que $81 \%$ dos autores dos casos de violência eram alunos. Em contrapartida, $77 \%$ das pessoas que sofriam a violência também eram os alunos.

A partir disso, o que se pode inferir é que pode haver falhas no sistema de resolução de conflitos dessas escolas que estão fazendo com que eles se tornem cada vez mais recorrentes e naturalizados.

Um meio bastante recente para mediar conflitos e que vem sendo difundido nos últimos anos pelo Brasil e pelo mundo são as práticas de mediação e as restaurativas. Estes meios alternativos de resolução de conflitos utilizam-se dos princípios de uma técnica dialógica chamada de Comunicação Não-Violenta, que tem no psicólogo Marshall B. Rosenberg o seu maior expoente e pensador.

A Comunicação Não-Violenta, que neste artigo abreviamos para CNV, segundo seu idealizador, se baseia em: "[...] habilidades de linguagem e comunicação que fortalecem a capacidade de continuarmos humanos, mesmo em condições adversas.”(ROSENBERG, 2006, p. 21).

Adiante, serão explicitados os princípios norteadores deste tipo de comunicação.

\subsection{Os princípios que norteiam a CNV}

Dentro do espectro do que foi exposto no tópico anterior, agora serão trabalhados com maiores detalhes os princípios que dão o norte para a aplicação das técnicas da CNV. Este conjunto de técnicas dialógicas idealizado por Rosenberg tem em sua concepção quatro princípios, são eles: observação, sentimentos, necessidades e pedidos.

O processo de observação, para Rosenberg (2006), deve ser feito sem avaliações, ou seja, deve-se tentar analisar a situação pelo que ela realmente é e não pela impressão que ela nos causa. Isso permite ao observador formar uma imagem mais limpa do que está acontecendo em determinada situação, tentando se afastar ao máximo do pensamento julgador. Diante disso, deve-se tentar entender que sentimentos estão a aflorar naquele momento observado.

No ponto dos sentimentos, Rosenberg (2006) levanta uma reflexão bastante interessante. Ele nos diz que as pessoas, em muitos casos, utilizam a palavra "sinto" de forma equivocada. E isso, para o processo de comunicação interpessoal, pode trazer prejuízos para o entendimento do que realmente se sente. Quando dizemos que: "sinto que sou um mau jogador de futsal", na verdade, estamos fazendo um julgamento das 
nossas habilidades nesse esporte e não expressando como realmente nos sentimos em relação a isso. Uma forma que poderia encaixar melhor para dizermos isso seria: "me sinto frustrado por não saber jogar bem futsal".

Neste momento, trataremos sobre a descoberta das necessidades humanas por trás da expressão dos nossos sentimentos. Marshall Rosenberg vai nos dizer que: “[...] O que outros dizem e fazem podem ser o estímulo, mas nunca a causa de nossos sentimentos" (ROSENBERG, 2006, p. 95 - grifo do autor). Dessa afirmação depreende-se que a pessoa precisa, na sua busca por libertação emocional, levar consigo a consciência de que tudo que ela sente, ou deixa de sentir, está atrelado a sua própria mente. As atitudes das outras pessoas podem estimular emoções das mais diversas no "eu”, porém ela só te abalará de acordo com seu estado psicológico no momento que você recebeu aquele estímulo, o que irá medir o grau do quanto aquilo te afetará.

Deste parágrafo em diante trataremos do quarto e último princípio da CNV, que se trata da forma como, ao observarmos uma situação, de forma a não julgá-la, refletiremos sobre os sentimentos e as necessidades que estão envolvidas nela, como também será formulado o pedido que visará atender e satisfazer estes últimos.

Para que um pedido possa ser bem recebido e atendido pelo interlocutor, faz-se necessário que ele seja feito com clareza e objetividade. Rosenberg (2006) traz à tona algumas maneiras de se fazer com que haja a diminuição das chances de um pedido soar como uma exigência que terá graves consequências para a pessoa que não puder cumpri-lo.

Com o objetivo de ter sua solicitação atendida, as pessoas devem deixar explicadas de forma clara os motivos (sentimentos e necessidades) por trás daquele pedido, explicitando o que elas querem que seja feito e não o que não deve ser feito.

Desta forma, trazendo para o ambiente escolar todos esses princípios explicados anteriormente, podemos ter um ponto de partida para se visualizar uma melhora nas relações interpessoais dentro das escolas do Brasil.

Após essa breve explanação acerca dos princípios que norteiam a CNV, o tópico seguinte falará sobre como ela tem sido aplicada no ambiente escolar brasileiro.

\subsection{Como a aplicação da CNV tem atuado no contexto escolar brasileiro}

De início, foi dada uma breve introdução sobre a relação entre a CNV e as escolas e também se discorreu sobre os pilares que norteiam esse conjunto de práticas dialógicas que tem o intuito de fornecer subsídios para melhor convivermos em sociedade. Nas linhas seguintes, abordar-se-á como a perspectiva que é dada ao conflito inter/intrapessoal pode ser fundamental.

Primeiramente, devemos tratar sobre a ideia de conflito. De acordo com a lição de Álvaro Chrispino: "Conflito é toda opinião divergente ou maneira diferente de ver ou interpretar algum acontecimento. A partir 
disso, todos que vivemos em sociedade temos a experiência do conflito." (CHRISPINO, 2007, p. 15). Tomando essa definição para o que é conflito e dada a sua ocorrência frequente nas mais diversas sociedades e espaços, dentre eles, o escolar, faz-se necessário que se questione e seja feita uma reflexão sobre o modo pelo qual essas situações são abordadas.

Refletindo acerca das abordagens dadas ao conflito, tem-se que há uma vista grossa de parte das pessoas. Em sintonia com esse pensamento, tem-se que Chrispino (2007) nos diz que geralmente só reparamos no conflito quando se explicita por meio da violência física, - a qual é o clímax de toda relação conflituosa - o que implica que houve certa falta de acompanhamento correto dos microconflitos que acabaram por desembocar nesse maior. Em nossa sociedade temos o costume de tratar o conflito como algo ruim e que deve ser abafado - reprimido - a todo custo.

E ao reprimirmos esse tratamento às relações conflituosas, é que elas vão se fortalecendo cada vez mais. Ora, se uma pessoa está acometida de dengue, por exemplo, não adianta ela fechar os olhos para a doença e simplesmente ignorá-la, isso vai fazer somente com que ela se desenvolva até um ponto em que fique insustentável. Nesse caso, deve-se tratar a chaga para que se retorne, no melhor cenário possível, à situação saudável que se encontrava anteriormente.

Como as doenças, as relações conflituosas também podem contagiar as pessoas ao redor dos envolvidos, mas também possuem mecanismos profiláticos para serem evitadas. E é neste contexto que se entra as questões concernentes à CNV para servir de técnica dialógica para prevenir o surgimento de conflitos.

Contudo, também para Chrispino (2007), o cenário de negação conflitual está mudando. Ao nos dizer que:

[...] O conflito começa a ser visto como uma manifestação mais natural, e, por conseguinte, necessária às relações entre pessoas, grupos sociais, organismos políticos e Estados. O conflito é inevitável e não se deve suprimir seus motivos [...]. (CHRISPINO, 2007,p. 17).

E é neste espectro que surge o uso da CNV, tendo como recorte o contexto escolar, para ser um mecanismo fortíssimo para a construção de uma Cultura de Paz e também para o empoderamento infantojuvenil e da sociedade ao dar aos jovens e a comunidade escolar o protagonismo das decisões naquele ambiente.

Em seu trabalho de pesquisa, Patrícia Krieger Grossi e seus colaboradores trazem alguns apontamentos a respeito da metodologia de educação para paz realizada em Porto Alegre/RS.

Inicialmente, cabe trazer o seguinte trecho para entendermos como se baseia a educação para a paz:

Na metodologia da educação para criação de uma comunidade e suas relações e começar a ligar a noção de paz com a de uma sociedade democrática e inclusiva. (GROSSI, et al, 2005, p. 8).a paz, há um tripé, que é a comunidade, a palavra e a ação. O primeiro passoéa

Grossi et al (2005) traz uma sugestão bastante válida para as escolas e que tem ligação íntima 
também com os processos decorrentes das práticas restaurativas ao se buscar meios para aumentar a autoestima dos jovens dentro da escola. A falta de valorização do aluno também é uma problemática seríssima em alguns locais do Brasil. Aquela pessoa não é somente um número, ou uma nota, demonstrá-las assim é desvalorizar sua individualidade.

A escola tratar seus alunos de forma digna, buscando seu empoderamento, até mesmo por meio de delegação de funções a eles dentro do ambiente estudantil pode ser extremamente benéfico para desenvolver neles um senso mais concreto de responsabilidade e de pertencimento àquele local.

Grossi et al (2005) corrobora em seu artigo o que foi dito anteriormente. Observou-se que ao trazer os alunos para dentro da escola nos fins de semanas e envolvê-los em atividades que visem à reparação do ambiente escolar, fez com que despertasse neles um sentimento de que aquilo os pertencia. E, de forma bastante satisfatória houve diminuição dos casos de depredação do patrimônio público naquele local.

Por fim, cabe sempre ressaltar a importância dessa inclusão da juventude nos espaços públicos para a consolidação de uma sociedade forte, unida e democrática. Ações que prezam pela não-violência, pelo diálogo e participação popular, como as trazidas acima devem ser vistas com bons olhos pelos gestores das escolas brasileiras e pelos órgãos do governo, pois elas têm trazido resultados realmente promissores.

No próximo capítulo serão analisados os relatos de facilitadores de práticas restaurativas sobre suas ações nas escolas da cidade de Mossoró/RN e quais foram os seus resultados obtidos, buscando entender quais foram os principais desafios enfrentados por eles e se notaram algum tipo de retorno positivo dessas instituições.

\section{A CNV EM AÇÃO NAS ESCOLAS DE MOSSORÓ/RN A PARTIR DA VISÃO DE FACILITADORES DE PRÁTICAS RESTAURATIVAS}

Neste capítulo, será trabalhada a parte empírica desta pesquisa. Esta foi construída a partir da análise das respostas fornecidas por meio de um questionário enviado por e-mail para alguns facilitadores de práticas restaurativas que realizaram ações nas escolas da cidade de Mossoró/RN. O critério utilizado para selecionar as pessoas participantes foi ter participado e concluído o curso de facilitação de práticas restaurativas, promovido pelo Ministério Público do Estado do Rio Grande do Norte (MPRN), e delimitou-se que seriam estudantes do curso de Direito da Universidade Federal Rural do Semiárido de Mossoró/RN.

No dia 26 de novembro de 2019, foram enviados e-mails para 14 facilitadores contendo o questionário (Apêndice 1) a ser respondido e o Termo de Consentimento Livre e Esclarecido (Apêndice 2). Desses e-mails, apenas 11 tiveram o recebimento confirmado pelas pessoas. Porém, apenas 7 foram respondidos, com o questionário preenchido até o fechamento da coleta de dados, que ocorreu em 29 de janeiro de 2020, sendo o último e-mail recebido em 09 de dezembro de 2019.

O público deste trabalho se distribui entre alunos e alunas que estão entre o terceiro e o oitavo semestre do Curso de Direito na UFERSA de Mossoró/RN e tiveram suas formações teóricas concluídas em 
um lapso temporal de, aproximadamente, 01 ano e 09 meses a 07 meses da data em que responderam ao questionário.

Nos tópicos seguintes serão analisadas as respostas dos entrevistados trazendo, em sequência, os desafios enfrentados por essas pessoas para levar essa prática dialógica de não-violência para um ambiente tão importante como o escolar. Em seguida, serão analisadas quais eventuais contribuições foram observadas pelos facilitadores de práticas restaurativas ao tentar aplicar as técnicas da CNV nas ações realizadas em escolas.

\subsection{Os desafios encontrados para aplicar a CNV no contexto escolar}

Primeiramente, decidiu-se por analisar as principais dificuldades relatadas pelos facilitadores de práticas restaurativas para poder levar as técnicas da CNV para dentro do ambiente escolar. Dentre os empecilhos que foram destacados por grande parte das pessoas, evidenciam-se principalmente a falta de conhecimento do que são as práticas restaurativas e a dificuldade de aproximação com a administração das escolas.

Outra problemática relatada por pessoas que realizaram as práticas restaurativas com crianças do ensino infantil foi certa dificuldade inicial em trazer a participação de uma das crianças para o diálogo dentro do círculo, ficando ela muitas vezes em silêncio quando chegava sua vez de falar. Porém, ao final, na hora de fazer comentários sobre a experiência vivida, ela se pronunciou e elogiou aquela situação que acabara de viver.

Houve relatos também de práticas restaurativas que foram realizadas com os profissionais das escolas e que, segundo a impressão do facilitador, eles se mostraram dispersos e sem tanto interesse em participar daquele momento restaurativo.

Cabe trazer também para esta discussão que uma das pessoas disse que acabou não enfrentando nenhuma dificuldade procedimental e de logística para realização da prática restaurativa em sua experiência. Isso se deu, no caso em questão, porque o Ministério Público do Rio Grande do Norte forneceu transporte para levar os facilitadores até a escola, que se localizava na zona rural de Mossoró.

Disse a pessoa também que a equipe da escola foi bastante aberta e receptiva a proposta de círculo de diálogo levada por ela para ser trabalhada com os jovens daquela escola. Entretanto, ela falou que sentiu falta da presença dos pais no ambiente, visto que o tema a ser tratado no espaço seria a prática de bullying - um dos tipos de violência mais recorrentes entre estudantes - naquela escola.

Diante do que foi apanhado nos relatos analisados, parece válido dizer que aparentemente o principal problema enfrentado pelos facilitadores de práticas restaurativas em levar as técnicas de comunicação nãoviolenta para o ambiente escolar perpassa principalmente, e ironicamente, por problemas de comunicação entre a equipe responsável pela escola e a pessoas que pretendem realizar estas ações lá.

Essa conclusão pode ser reforçada tendo como base as próprias palavras dos facilitadores. Como 
vemos a seguir:

\begin{abstract}
O maior problema foi o de comunicação. Em nenhuma das escolas que visitei havia pessoas que soubessem sobre a Justiça Restaurativa ou o que suas práticas podiam proporcionar no ambiente escolar, o que, de início gerou certo receio. Paralelamente, a direção e coordenação de algumas das escolas se mostraram indisponíveis para um momento de diálogo anterior à realização das ações, o que dificultou a realização da prática no dia disponibilizado.
\end{abstract}

O trabalho de inserção dessas práticas dentro das escolas e mesmo a ampliação delas para a sociedade geral vai passar muito pela problemática da falta de informações sobre o que seriam esses momentos restaurativos e como eles funcionariam de forma positiva para agregar valores de paz na convivência entre as pessoas.

Refletindo sobre o problema da falta de informações sobre os processos restaurativos que envolvem boa parte da sociedade, temos o seguinte relato que entra em sintonia com o que foi falado anteriormente. Vejam: “[...] afirmo que a maior dificuldade encontrada por mim foi com os profissionais da unidade escolar que, por mais que tenham gostado, não se abrem completamente para ela [...]”.

Acerca disso, também é necessário falarmos sobre a questão da jornada de trabalho dos funcionários e das pessoas que formam a comunidade externa, como também, e em igual importância, as outras diversas preocupações que os próprios estudantes, principalmente os de baixa renda e frequentadores de escolas públicas, enfrentam para poderem se fazer presentes no ambiente escolar. Por exemplo, tem-se o caso daqueles professores ou porteiros que trabalham em mais de uma escola ou algum outro estabelecimento para poder complementar a sua renda mensal.

Da mesma forma existem estudantes que se veem quase que obrigados pelas necessidades de sua residência a buscar algum emprego de meio turno para ajudar nas finanças de casa, o que pode acarretar, inclusive, a sua própria evasão escolar ou simplesmente trazer a questão financeira para o primeiro plano em sua vida, deixando os estudos em segundo plano.

Dentro desse espectro de dificuldades, torna-se compreensível a indisponibilidade eventual dessas pessoas para se abrir a participação em um momento com ações alternativas que são desconhecidas por eles e podem gerar o pensamento que seria mais uma coisa para eles se preocuparem. Isto pode ser contemplado pelo seguinte comentário constante em um dos questionários respondidos, no qual a pessoa comenta sobre eventuais motivos causadores da indisponibilidade de algumas pessoas: "seja por não acreditar nas potencialidades da Justiça Restaurativa, seja por terem jornadas tão exaustivas e em tantos lugares que não conseguem encontrar espaço em seus calendários para a realização de projetos como este.”

Ao passo que fizemos os devidos comentários acerca dos relatos que trouxeram as dificuldades encontradas pelos facilitadores de práticas restaurativas nas ações realizadas nas escolas, passaremos a fase seguinte deste trabalho.

Logo adiante, traremos o que foi analisado das respostas dos facilitadores quando a pergunta feita tratava sobre o retorno concernente aos possíveis benefícios observados por eles nas práticas restaurativas 
realizadas nas escolas provenientes seja do corpo docente, seja da equipe técnico-administrativa ou das famílias e comunidade externa.

\subsection{As possíveis contribuições observadas com a aplicação da CNV no ambiente escolar de Mossoró/RN}

Neste tópico, traremos os relatos dos facilitadores de práticas restaurativas no tocante ao retorno que estes tiveram das escolas após a realização das práticas restaurativas ministradas por eles nestes espaços. Buscou-se saber se houve retornos positivos e quais são as possíveis contribuições que os facilitadores julgam que pode a CNV levar para este ambiente, tão ímpar para o desenvolvimento humano, que é o escolar.

Fazendo um apanhado geral, as respostas trouxeram um teor extremamente positivo de como os participantes das práticas restaurativas nas escolas reagiram a aquele momento. Gratidão, alívio e a sensação de que finalmente puderam ser ouvidos de coração foram retornos citados por todos os questionados ao falarem sobre os aspectos positivos advindos daqueles momentos restaurativos.

Como foi feito no capítulo anterior, traremos, neste momento, a transcrição da fala de algumas pessoas que foi obtida a partir do questionário.

Com o intuito de fortalecer o que foi dito nas linhas anteriores, logo abaixo teremos o seguinte trecho de resposta para ilustrar o que foi dito pelos facilitadores ao responderem a seguinte pergunta: “Agora, olhando por outra perspectiva, que retornos positivos você obteve dos alunos e do corpo docenteadministrativo das escolas?"

Uma das respostas foi a seguinte:

Nos círculos que participei, notei um sentimento de gratidão e alívio do corpo docenteadministrativo por finalmente estarem sendo realmente ouvidos, sem julgamentos. Ao final do círculo, várias das professoras presentes pediram para voltarmos mais vezes, o que, infelizmente, não ocorreu ainda. Mas a experiência, acredito, foi proveitosa para todos os participantes.

Essas mensagens positivas certamente deixam as pessoas que trabalham com esta forma não violenta de abordar situações do dia a dia bastante animadas para seguir em frente disseminando essas práticas em diversos ambientes. Ver retornos positivos, incluindo a abertura da escola para receber outras ações como essas são de importância imensurável para a continuidade dessas práticas e até mesmo institucionalização delas naquele ambiente, visto que pode chamar a atenção das Secretarias de Educação e a busca por mais informações sobre o tema. Por isso, torna-se bastante animador e gratificante ler relatos como o seguinte:

\footnotetext{
Após alguns meses da realização de um círculo, por exemplo, recebemos uma mensagem da diretora da escola agradecendo, mais uma vez, pela nossa atuação e nos informando o quanto melhorou a comunicação entre professores e alunos, e entre as crianças, colegas de sala.
}

A comunicação entre professores e alunos, dentro da sala de aula, principalmente, é de extrema importância para a boa convivência dentro daquele espaço. Isso entra em consonância com o que é dito por 
Gabriel Henrique Santos Figueiredo e Diana Cláudia Freire em seu artigo:

\begin{abstract}
A criação de novos canais de comunicação com um propósito educativo entre professor e aluno e entre os próprios alunos utilizando situações do cotidiano favorece a diminuição de conflitos em sala de aula e ainda estimula uma reflexão do aluno sobre o seu espaço, seus direitos, seus deveres e seu papel na sociedade. (FIGUEIREDO, FREIRE, 2011, p. 3)
\end{abstract}

Um desses novos canais de comunicação pode muito bem ser acessível através de uma comunicação não-violenta dentro da sala de aula, visando a gestão democrática do ambiente escolar e uma maior participação estudantil.

Em sentido concorrente a esses retornos positivos das práticas restaurativas, temos também as contribuições que a sua técnica dialógica, a CNV, pode nos dar.

Dentro da constatação vista aqui nesse comentário de um facilitador sobre o contexto vivido nas escolas: "O ambiente escolar é onde os valores das crianças e jovens são formados, mas sabemos o quanto esse ambiente pode ser tóxico e opressivo se não houverem [sic] cuidados." Podemos trazer ao debate a necessidade de se buscar os valores humanos mais puros e bons como forma de remediar esses problemas.

Seguindo essa linha de raciocínio torna-se impossível não concordar com a seguinte frase dita por um dos facilitadores ao nos suscitar quais valores bons e puros poderiam ser exercitados no contexto escolar. Veja-se: "quando inserimos A CNV nesse contexto, ajudamos a humanizar o ambiente escolar e a inserir valores como o respeito e a empatia."

Diante do exposto, percebe-se que trazer à tona a empatia, o direito de realmente ser ouvido e diminuir as barreiras na relação professor-aluno e tantas outras que existem dentro das escolas é um ponto crucial para o melhoramento do ambiente escolar e tornar ele cada vez mais um ambiente confortável para se atingir a sua finalidade principal que é o aprendizado.

Essa percepção vê-se reforçada pelo seguinte relato acerca da $\mathrm{CNV}$ e das práticas restaurativas:

Ao prezar pelo diálogo para resolução de conflitos ou qualquer outro problema, ela não somente empodera os sujeitos, mas também atua como um meio impulsionador a assunção de responsabilidades e incentivador do desenvolvimento de empatia pelo próximo.

A esperança de um futuro melhor para as próximas gerações e para um desenvolvimento mais saudável da que está em crescimento neste momento certamente tem um ponto de apoio fortíssimo na CNV, visto que a composição de um ambiente escolar pautado nas práticas alternativas de resolução de conflitos e, torna-se a dizer, na gestão democrática pode ser extremamente benéfica para a construção de uma sociedade em geral cada vez mais democrática e justa.

No próximo capítulo serão abordadas maneiras pelas quais se podem, junto com outros agentes envolvidos no contexto escolar, tornar mais fortalecidas as práticas restaurativas dentro dos ambientes escolares por meio da abordagem dialógica proposta pela $\mathrm{CNV}$. 


\section{ESTRATÉGIAS PARA FORTALECER AS PRÁTICAS RESTAURATIVAS ESCOLARES POR MEIODACNV}

Neste capítulo, traremos alguns pontos estratégicos que podem ser utilizados nas escolas para que sejam fortalecidas as práticas restaurativas e o processo de empoderamento dos alunos para a construção de uma democracia escolar participativa e forte.

Com essa finalidade, no primeiro tópico será abordada a questão de como o corpo docenteadministrativo das escolas, composto por professores, direção e demais funcionários pode - e, inclusive, deve - ser incluída nas práticas restaurativas realizadas nas escolas. A necessidade de inclusão destes agentes deve se dar principalmente porque se entende que é de extrema importância entender como eles se sentem naquele ambiente e se suas necessidades pessoais e profissionais estão sendo correspondidas ali.

Em tópico posterior abordaremos a questão familiar. Esse ponto também é de extrema importância, pois a família é um dos pilares fundamentais na vida do jovem e com o apoio - ou falta dele - na vida deste, tem-se todo um direcionamento diferenciado nos rumos a serem trilhados por aquele ser humano. Entender a situação da família dos alunos, como ela se configura, que dificuldades passam, podem, inclusive, facilitar práticas de ações voluntárias operacionalizadas pela própria escola para remediar alguns problemas.

Por exemplo, se uma família com baixo poder aquisitivo está a passar por dificuldades financeiras, e por meio de rodas de conversa no ambiente escolar, foi possível diagnosticar esse problema, há grandes possibilidades de toda aquela comunidade escolar se prontificar a ajuda-los de alguma forma, se eles quiserem e se sentirem à vontade para receber ajuda.

Feito esse breve resumo do que será tratado no tópico seguinte, aprofundaremos o assunto adiante.

\subsection{O papel do corpo docente-administrativo no fortalecimento das técnicas de CNV}

Como trazido de forma resumida no tópico anterior, neste momento serão feitas considerações acerca do papel do corpo docente-administrativo e do restante dos funcionários das escolas para fortalecer o ideal de uma escola pautada na cultura de paz e na CNV. Em geral, as escolas, em questões administrativas, têm no topo de sua pirâmide hierárquica a figura dos ou do Diretor, que pode ou não ter unificado sob seu poder a direção administrativa e a direção pedagógica da escola.

Logo abaixo na linha de hierarquia estão os coordenadores, a quantidade destes depende do tipo de escola, se esta é somente para nível infantil, fundamental ou médio. No caso de uma escola que possua os três níveis, há casos em que cada nível é regido por um coordenador.

No terceiro estrato têm-se os professores e demais funcionários da escola, que podem ser da mais diversa quantidade e desempenhar várias funções, dependendo da sua aptidão profissional. Por fim, temos, na base da pirâmide, os alunos e, porque não dizer, a comunidade que também participa daquela escola, como pais, vizinhança e etc., e eles, por estarem na base, acabam por dar a firmeza da qual se necessita para a 
manutenção da estabilidade em toda essa "construção".

Em qualquer curso de engenharia que se trabalhe com a construção de edifícios, o engenheiro, em seu saber técnico, tem o conhecimento que aquela obra só pode se manter firme em pé, do jeito que se espera, se todas as suas partes estiverem atuando perfeitamente em conjunto. Da mesma forma funciona a configuração estrutural das escolas, cada estrato pode ser visto como um andar que se faz base para a construção do outro que virá por cima.

Desta forma, é cabível dizer que a relação entre as partes componentes do ambiente escolar deve ser harmônica e, principalmente, deve conversar entre si para que se mantenha um lugar agradável para se trabalhar. É necessário também termos atenção para a saúde mental de professores, funcionários e pessoas envolvidas na parte administrativa das escolas. Esse corpo de trabalhadores precisa estar com a sua motivação em dia para poderem estar inspirados a fazerem o seu trabalho da melhor forma possível e levar um ensino de qualidade aos jovens que os esperam na sala de aula.

Fazendo um breve recorte para falar sobre a questão da saúde no ambiente escolar, será falado um pouco sobre os problemas que têm surgido com relação à saúde dos professores diante da modernização dos métodos de ensino.

O processo pedagógico perpassa pela figura do professor como um dos principais polos nessa relação e para esta categoria poder coordenar a disciplina dentro de sala de aula e tentar repassar certo conhecimento para o seu público ouvinte, é necessário que a sua saúde mental e vocal estejam em dia para atingir este fim.

Em pesquisa realizada por Delcor et al. (2004) na rede de ensino particular na cidade de Vitória da Conquista/BA, pôde-se observar que, numa amostra de 250 professores (as), 94,8\% destes responderam a pesquisa solicitada pela pesquisadora e seus colaboradores (as), e, a partir disso, obteve-se que 41,5\% destas pessoas relataram sofrer com algum tipo de distúrbio psíquico menor.

Desta mesma pesquisa também foi possível ter em mãos dados acerca de problemas vocais dos professores (as) daquela rede de ensino. Vejamos: de uma amostra de 245 professores (as) viu-se que 45,7\% relataram sofrer de forma frequente ou muito frequente de dores de garganta. Como também, em uma amostra um pouco menor, de 240 educadores (as) 22,5\% disseram sofrer com perda temporária da voz.

Tendo esses dados em mãos, podemos dizer que eles demandam atenção do Estado e dos gestores das escolas privadas, para melhor auxiliar na manutenção da saúde de seus funcionários. Com a evolução do sistema de ensino brasileiro, houve uma intensificação do trabalho da classe dos professores (as), pois agora a estes e estas são delegadas funções diversas da de lecionador dentro das salas de aula.

A situação descrita por Assunção (2005) e citada por Ada Ávila Assunção e Dalila Andrade Oliveira (2009) em sua pesquisa, exemplifica o que foi dito no parágrafo anterior. Vejamos: É narrada uma história na qual uma professora se encontrava em sala de aula com uma criança que estava acometida com um quadro febril e ela estava dividindo sua atenção em dar continuidade a aula e verificar a situação de saúde da criança, enquanto buscava contatar a família para que viessem buscar a criança. Não havia forma de contato com o 
centro de saúde mais próximo para levar a criança para ser tratada lá.

Situações como esta colocam o profissional educador em situações de extrema urgência e tensão emocional, visto que pode fazê-lo sentir-se impotente diante de alguma problemática que apareça para ele resolver. Isso os enquadra como um grupo suscetível aos problemas relacionados com a saúde mental, como o cansaço emocional e, em casos mais graves, até mesmo quadros de ansiedade e depressão.

Desta forma, retomando o pensamento do início deste tópico, torna-se a dizer que é imprescindível para o bom funcionamento da escola que os seus setores possuam harmonia entre si e, além disso, deve haver funcionários suficientes que possam atender aos problemas de uma forma mais específica.

Portanto, trazendo para o ambiente escolar, o número adequado de pessoas para que elas ajam dentro do que sua formação acadêmica e vivencial os habilitou a exercer, evita-se que pessoas sejam sobrecarregadas dentro das instituições escolares. Por isso, é imperativo ao Estado manter profissionais da área do serviço social e da psicologia dentro do quadro de funcionários para não delegar a um diretor, ou qualquer outra pessoa da escola, que não tenha formação na área, para resolver conflitos de cunho social e afins dentro das escolas.

Com isso em vista, pode-se ter como esperança que havendo a construção de um corpo docenteadministrativo de forma plural e multidisciplinar, com capacitação para identificar e intervir dentro das questões dos relacionamentos e suas crises, podendo usar como técnica dialógica norteadora e inclusiva, a $\mathrm{CNV}$, dentro daquele espaço das instituições escolares, pode ser um fator extremamente positivo para a construção de uma cultura de paz e a consolidação da gestão democrática dentro das escolas.

Em resumo, tem-se de atentar pelo zelo com a saúde mental do corpo de funcionários das escolas, não devendo deixá-los sobrecarregados com as diversas tarefas que lhes podem ser exigidas dentro daquele ambiente, como narrado durante o texto, e deixar-lhes vulneráveis a sérios problemas de saúde, como os vocais e de saúde mental. Por conseguinte, devem-se trazer para a equipe das escolas as mais diversas formações para que possam ser mais eficazes nas resoluções de conflitos que são inerentes àquele ambiente.

No próximo tópico, abordaremos como a presença da família no convívio escolar pode ser benéfica ou não para a questão do aproveitamento escolar e qual a sua função no fortalecimento das boas práticas de convivência dentro das escolas e no tocante a interação com a comunidade que as rodeiam, por meio da utilização de uma forma não violenta de se comunicar.

\subsection{A presença e a função da família para a construção de uma escola fortalecida por meio da CNV}

Neste último tópico, por fim, falaremos um pouco sobre a questão da família dentro do contexto escolar brasileiro. Resgatando o exemplo da pirâmide dado no tópico anterior, nós podemos dizer, novamente, que a família, junto com a comunidade que rodeia a escola, e os alunos, compõem a base da pirâmide hierárquica do ambiente escolar. Devemos lembrar, porém, que essa hierarquia baseia-se somente no tocante às funções exercidas por cada agente, não tendo relação com um valor maior ou menor das ações 
das ações das pessoas envolvidas nelas.

Em seu trabalho de pesquisa bibliográfica acerca das relações família-escola, Oliveira e MarinhoAraújo (2010) nos trazem que a família seria o primeiro contato do novo ser humano com o mundo, mostrando-lhe a visão deles a partir do contexto social em que estão inseridos.

Neste trabalho seguiremos a definição de família utilizada por Trost (1995) e citada na pesquisa de Oliveira e Marinho-Araújo (2010) que nos diz que: família é composta, minimamente, por duas pessoas, sendo levadas em contas as diversas orientações sexuais e também a paternidade/maternidade exercida de maneira solo, levando em consideração que as pessoas envolvidas na relação morem na mesma residência.

Tomando o que foi dito acima como ponto de partida, nós temos que a família, inicialmente, será a responsável, no início da vida humana, por apresentar os costumes e as maneiras de agir daquela sociedade na qual estão inseridas para aquela criança. Este seria o primeiro contato da criança com processos educacionais, mesmo que este não siga toda a metodologia do que é utilizado dentro das salas de aula para repassar conhecimentos. Desta forma, a família tem um papel essencial na formação da compreensão de mundo e adequação comportamental inicial da criança seguindo os preceitos da comunidade em que ela e sua família vivem.

Quando a criança adentra ao sistema escolar, ela continuará a estudar todo esse arcabouço cultural que o envolve e foi apresentado por sua família. Entretanto, na escola temos que isto será aprofundado, ao ser explorado em sala de aula os conceitos e as bases históricas que fizeram a nossa sociedade chegar ao ponto que vivemos hoje em dia. Diante disso, podemos inferir que, idealmente, o trabalho feito por família e escola tende a ser complementar e deve ser feito a base de trocas de experiências entre as partes envolvidas, com o intuito de ser otimizado.

Entretanto, isso não é visto com tanta frequência quanto deveria nas escolas, sendo percebido que na verdade há um enfrentamento, mesmo que velado, entre escola e família no que diz respeito a forma de conduzir o processo de aprendizado e o modo como se dá a comunicação entre os agentes envolvidos nessa relação. De acordo com Oliveira e Marinho-Araújo (2010, p. 102) o que se tem, na verdade, é “um movimento de culpabilização e não de responsabilização compartilhada". Essas situações acabam por afastar as famílias do convívio mais próximo das escolas, e pode limitá-las a se fazerem presentes somente nos eventos organizados pelas escolas, como as festas comemorativas e reuniões de pais.

Polonia e Dessen (2005) em seu trabalho, tendo como base as pesquisas de Costa (2003); Fonseca (2003); Marques (2002); vão nos dizer que existem benefícios com a integração entre família e escola, principalmente quando o projeto pedagógico abre espaço para que a família possa participar ativamente dentro da escola e também é reconhecida como um papel diferenciado, porém de extrema importância para o processo de aprendizagem.

Para exemplificar o quanto uma relação próxima entre pais e escola pode ser extremamente positiva, tem-se a experiência vivida no primeiro ano do ensino fundamental de uma escola na cidade de Limoeiro do Norte/CE. Nesta turma, uma das mais importantes para a formação escolar, no início do ano letivo é criado um 
grupo em uma rede social que congrega os pais dos alunos e a professora. Nele são debatidos diversos assuntos concernentes ao andamento das aulas e a evolução dos alunos dentro do espaço escolar.

Esse sistema permite um canal direto de comunicação entre escola e família. Ademais, diante da grande celeridade do processo de informação com advento das redes sociais, essa porta de comunicação abre espaço para um retorno mais rápido e direto dos pais acerca de como receberam a informação dada.

É costumeiro também nessa turma, o envolvimento direto dos pais na elaboração dos projetos que são feitos com o intuito de serem apresentados na feira de ciências do colégio. Desta forma, é visto que os pais participam ativamente da vida escolar dos seus filhos e filhas, e, além disso, há a integração entre as próprias famílias em si, visto que se faz necessário realizarem-se reuniões para debater sobre como serão feitos os trabalhos.

Infelizmente, essa proximidade não se consolida ao longo da evolução do jovem dentro da vida escolar. No caso desta escola, no ensino médio não existe mais esse grupo que una pais e professores para debater os assuntos estudantis. O que, consequentemente, faz com que o estudante vire mero porta recados para comunicar seus pais do acontecimento de algum evento que teve ou virá a ter na escola.

Então, de que forma poderemos fortalecer a participação da família dentro do ambiente escolar e como a CNV pode estar envolvida nisso?

O fortalecimento de vínculos entre família e escola perpassa principalmente pela comunicação. Essa comunicação deve ser feita de forma efetiva e clara, proporcionando o entendimento para todas as partes envolvidas naquele ambiente escolar. $\mathrm{A} \mathrm{CNV}$ entra em ação nesse caso, ao buscar trazer à tona as necessidades e sentimentos envolvidos dentro da relação família-escola.

No polo da família, principalmente as de baixa renda e com um nível de escolaridade não tão alto, tem-se muito da questão da autoestima dos pais em não se sentirem com "nível" para dar alguma sugestão do que deva ser feito para melhorar o rendimento de seus filhos e como se devem proceder as situações internas da escola. Isso pode ser trabalhado com práticas restaurativas em busca de empoderar essas pessoas para que falem sobre seus sentimentos e façam uso de seu poder de fala para questionar algo que não lhe agrade na gestão da escola na qual estão inseridas pessoas que estão sob sua tutela.

No polo escolar, deve-se abrir as portas para a família e comunidade que circunda a escola se fazerem presentes, de forma democrática, na construção dos espaços de eventos realizados pelas escolas e também nas ações de extensão realizadas por elas. Sendo direcionadas para satisfazer alguma chaga social que atinja o bairro no qual a escola está inserida, ou até mesmo a própria cidade.

O debate sobre as relações família-escola são bastante proveitosos e longos, porém, infelizmente, ainda não possui um vasto acervo bibliográfico sobre o contexto nacional com dados mais concretos sobre o assunto. Porém, devemos seguir buscando nos informar mais e mais acerca dessa temática para que se torne algo de conhecimento geral e, a partir daí, aumentem-se as chances de surgirem medidas inovadoras para lidar com as problemáticas que envolvem toda essa questão.

Dito isso, partir-se-á agora para as considerações finais deste trabalho. 


\section{CONSIDERAÇÕES FINAIS}

Diante de tudo que foi trabalhado nesse texto, partiremos agora para as conclusões que vieram a partir do que foi construído nesta pesquisa.

De início, tomando como base os dados de uma pesquisa que nos forneceu alguns números acerca das violências vivenciadas nas escolas da rede estadual do Sergipe, foi possível visualizar que dentre os principais tipos de violência estavam presentes a violência verbal e a psicológica. A partir disso, foi possível fazer relação com as técnicas dialógicas da Comunicação não-violenta (CNV) e pontuá-las como um meio de se remediar os micro conflitos que se desenham no dia a dia da convivência escolar, com o intuito de diminuir as chances de se tornar um conflito de maior proporção, como os que acabam desembocando em agressões físicas.

Avançando dentro do trabalho, buscou-se descobrir as dificuldades enfrentadas e quais seriam as eventuais contribuições que a aplicação das técnicas de comunicação não-violenta teria no contexto escolar sob a ótica dos facilitadores de práticas restaurativas. Como principais dificuldades que foram postas perante os facilitadores de práticas restaurativas ressaltaram-se a falta de conhecimento do público alvo do que seriam as práticas propostas por aquelas pessoas e também, ironicamente, parte dos relatos nos expôs que problemas de comunicação com a administração das escolas também se configuraram como empecilhos.

Paralelamente, os relatos evidenciaram a existência de contribuições decorrentes da realização das práticas restaurativas nas escolas. De acordo com o que foi obtido através das experiências contadas pelos facilitadores, palavras positivas como alívio, gratidão e sentimento de paz imperaram como feedback das ações realizadas nas escolas. O ponto que mais nos mostra o retorno positivo de trabalhar esse tipo de ação no ambiente escolar é justamente a abertura para que sejam realizadas novamente, principalmente pelo efeito empoderador que essas práticas permitem a quem se dedica a elas.

Por último, buscou-se identificar estratégias de fortalecimento das práticas restaurativas vivenciadas no contexto escolar, com o intuito de aperfeiçoar sua aplicação nesse ambiente. Em nosso entendimento, as estratégias para se fortalecer as práticas restaurativas nas escolas perpassam por uma atuação conjunta entre a família, o corpo docente-administrativo e, porque não dizer, a comunidade que circunda a escola. Esses agentes, juntamente com os alunos, demonstram-se como bases fundamentais para o bom andamento escolar com fins de se atingir uma educação efetiva e dialogada entre as pessoas que estão envolvidas nesse processo.

\section{REFERÊNCIAS BIBLIOGRÁFICAS:}

ASSUNÇÃO, Ada Ávila; OLIVEIRA, Dalila Andrade. Intensificação do trabalho e saúde dos professores. Educ. Soc., Campinas, v. 30, n. 107, p. 349-372, maio/ago. 2009. Disponível em: http://www.cedes.unicamp.br. Acesso em: 10 de janeiro de 2020.

CHRISPINO, Álvaro. Gestão do conflito escolar: da classificação dos conflitos aos modelos de mediação. 
Ensaio: aval. Pol. Públic. Educ, Rio de Janeiro, v.15, n. 54, p. 11-28, janeiro/março de 2007. Disponível em: < http://www.scielo.br/pdf/ensaio/v15n54/a02v1554.pdf> . Acesso em 17 de novembro de 2019.

DELCOR, Núria Serre et al. Condições de trabalho e saúde dos professores da rede particular de ensino de Vitória da Conquista, Bahia, Brasil. Cad. Saúde Pública, Rio de Janeiro, v. 20, n. 1, p.187-196, fev. 2004.

FIGUEIREDO, Gabriel Henrique Santos. FREIRE, Diana Cláudia. Os desafios da relação entre professor e aluno no processo de ensino e aprendizagem. Maiêutica - curso de ciências biológicas, v.01, n. 01 Jul/Dez. 2011. Disponível em: https://publicacao.uniasselvi.com.br > BID_EaD > article > download. Acesso em: 11 de dezembro de 2019.

GROSSI, Patrícia Krieger; AGUINSKY, Beatriz Gerhenson; BRANCHER, Leoberto; OLIVEIRA, Simone Barros de; SCHNEIDER, Gisiane. Violência no meio escolar: a inclusão social através da educação para a paz. Textos \& Contextos, Pontifícia Universidade Católica do Rio Grande do Sul, Porto Alegre, v. 4, n. 1, p.
$1-16$,
$\mathrm{d}$ e $\mathrm{z}$ e $\mathrm{m} \mathrm{b}$ r o
d e
20005.
D i s p o n í v e 1
e $\mathrm{m}$ :

http://revistaseletronicas.pucrs.br/fass/ojs/index.php/fass/article/view/992. Acesso em 16 de novembro de 2019.

ROSENBERG, Marshall Bertram. Comunicação não violenta: técnicas para aprimorar relações pessoais e profissionais. 2. ed. São Paulo: Ágora, 2006.

SANTOS, Maria Angélica da Silva Costa. A comunicação não violenta como instrumento para uma cultura de paz: uma proposta para as escolas da rede estadual de Sergipe. Ideias \& Inovação, Aracaju, v. 4, n. 2, p.89-
102 ,
$\mathrm{m}$ a i o
d e
$\begin{array}{llll}2 & 0 & 1 & 8\end{array}$.
D i s p o n í v e 1
e $\mathrm{m}$ :

https://periodicos.set.edu.br/index.php/ideiaseinovacao/article/view/5611. Acesso em 15 de novembro de 2019.

OLIVEIRA, Cynthia Bisinoto Evangelista de; MARINHO-ARAÚJO, Claisy Maria. A relação famíliaescola: intersecções e desafios. Estudos de Psicologia, Campinas, v. 27, n. 1, p. 99-10., jan./mar. 2010. Disponível em: htp: //www. scielo. br/scielo. phpcscript=sci_artexttpid=S0103166X2010000100012tlng=entnrm=iso. Acesso em: 8 de janeiro de 2020.

POLONIA, Ana da Costa; DESSEN, Maria Auxiliadora. Em busca de uma compreensão das relações entre família e escola. Psicologia Escolar e Educacional, São Paulo, v. 9, n. 2, p. 303-312. Disponível em: http://www.scielo.br/scielo.php?pid=S1413-85572005000200012\&script=sci_abstract\&tlng=pt Acesso em: 8 de janeiro de 2020. 


\section{APÊNDICES}

\section{APÊNDICE 1 - QUESTIONÁRIO}

1. Qual curso de graduação e semestre está cursando?

2. Há quanto tempo você recebeu a formação de facilitador de círculos restaurativos?

3. Nos círculos restaurativos nas escolas de Mossoró e cidades próximas que você participou, quais foram as dificuldades enfrentadas?

4. Agora, olhando por outra perspectiva, que retornos positivos você obteve dos alunos e do corpo docente-administrativo das escolas?

5. A partir das suas experiências, como você vê a contribuição da Comunicação não violenta para o ambiente escolar? 